\title{
HIGH-SPEED RAIL SERVICES IN SPAIN AND THEIR RELATIONSHIP TO POPULATION GROWTH
}

\author{
JOSÉ LUIS MIRALLES I GARCIA \\ Department of Urban Planning, Polytechnic University of Valencia, Spain
}

\begin{abstract}
High-speed rail (HSR) services started in Spain in 1992. Today in Spain, there are 2,514 km of HSR with International Union of Railways (UIC) width. Between 1992 and today, 26 years later, several economic cycles have taken place in Spain: the economic crisis of 1991-1996, the economic expansion of 1997-2007 and the economic crisis of 2008-2018. Therefore, it is possible to analyse the behaviour of different cities with HSR services including periods of economic expansion and crisis. Different authors have studied urban development dependent on HSR services in different countries. This question is not simple. According to classical theory, new transport infrastructure brings comparative advantages to cities with new services, but, although necessary, transport infrastructure is not sufficient to bring about economic development. Previous research has analysed the relationship between HSR services and population growth for those cities with HSR services, as opposed to all cities without HSR services and, particularly, the case of inland small cities with/without HSR services. On the other hand, in Spain, there are four large groups of cities: cities in metropolitan areas, coastal small- to medium-sized cities, inland small- to medium-sized cities and very small cities. This article shows the research into the relationship between HSR services and population growth in metropolitan areas and coastal small-medium cities from 1992 to today. This research complements the findings of previous research. The results show that, in general but not always, new HSR services are associated with greater population growth as an index of economic growth. Therefore, the results contrast with the hypothesis that infrastructure is necessary but not enough to bring about economic growth, and this economic growth also depends on other factors such as city size, distance to core city and the city's own economic activities.
\end{abstract}

Keywords: HSR territorial impact, regional development, urban development, cities’ system.

\section{INTRODUCTION}

High-speed railway (HSR) services began in Spain in 1991, 27 years ago. In fact, the Rail Transport Plan to improve conventional train services and Spain's railway network was approved in 1987. However, a few years later, the Spanish government decided to cancel the plan and execute the first high-speed line (AVE services, in Spanish) between Madrid and Seville, which opened during the Universal Exposition of Seville in 1992. With speeds of about $300-350 \mathrm{~km} / \mathrm{h}$, this service launched Spain's new railway network with International Union of Railways (UIC) gauge (in Spain, all conventional train networks have Iberian gauge, which differs from UIC). Investment in this infrastructure consumed all the planned budget for the conventional rail plan. The station for high-speed trains in Madrid was located at Atocha Station in the city centre.

Progressively, according to the reports of ADIF (Spanish acronym of Administrative Manager of Railways Infrastructures) [1] and VIA LIBRE [2], the new rail network increased. As the high-speed network has expanded, passenger numbers have also increased [3], as can be seen in Fig. 1. Fig. 2 shows the HSR network in Spain in 2017. Note that the number of passengers is low in relation to the length of high-speed lines built. According to Albalate and Bel [4], [5], the length of the Spanish high-speed rail network is more extensive than the networks of France, Germany or Japan, because of the ratio of network $\mathrm{km}$ to inhabitants in Spain is very high. 
The fact that, historically, the rail network has a different width from that of the general European gauge has conditioned much decision-making [6]. In general, instead of prioritizing the transformation of conventional lines with more passenger traffic, successive governments have opted for an extensive transformation of the entire network to serve the greatest number of cities with passenger services, with a radial network always originating in Madrid, as Bel explains [7].

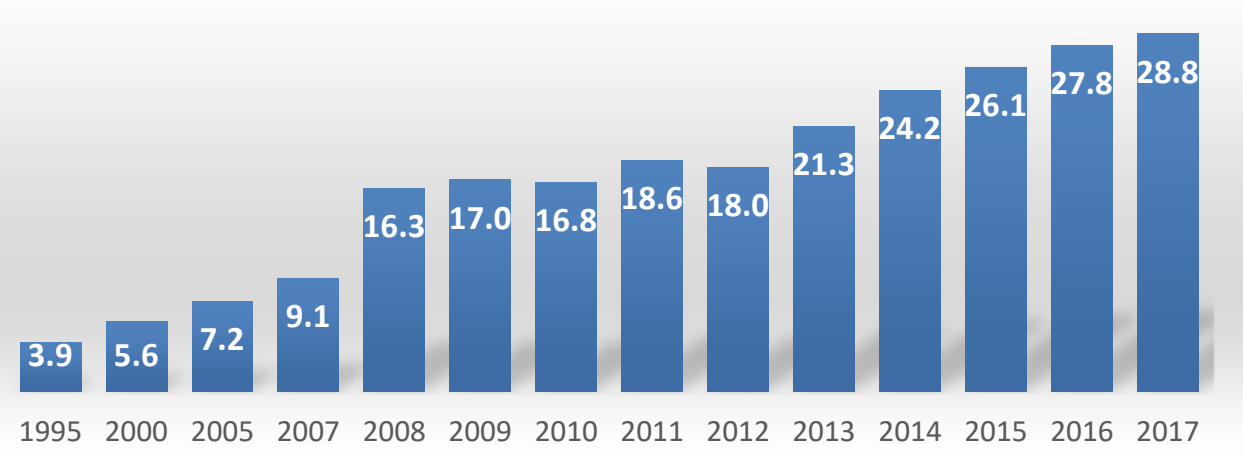

Figure 1: Evolution of passengers using HSR in Spain (millions). (Source: Ministerio de Fomento (Spain) and RENFE-OPERADORA.)

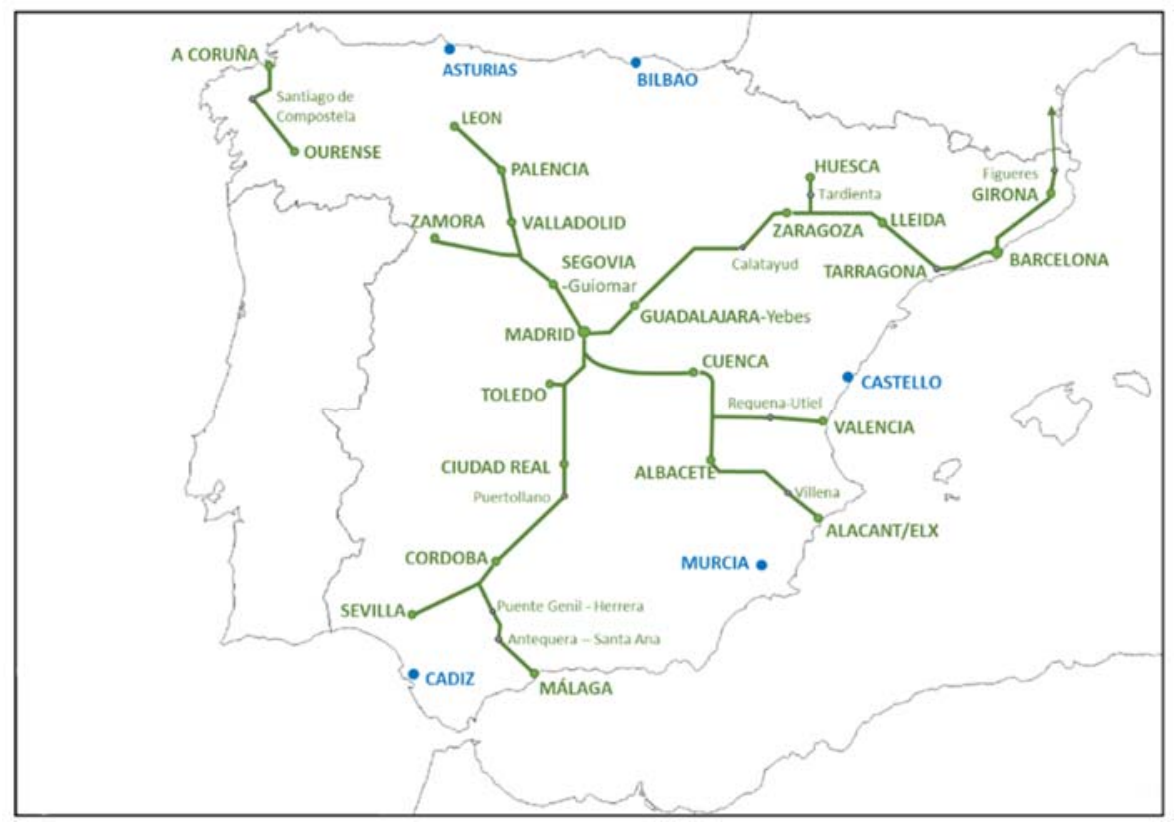

Figure 2: Network high-speed railway in Spain in 2017 and main coastal urban areas without HSR services. (Source: ADIF and author.) 
To increase the use of the new infrastructure, ADIF improved services with "average distance trains". These services connect cities relatively close to each other and allow travellers to commute. In these cases, the average speed of travel is about $200 \mathrm{~km} / \mathrm{h}$, lower than in the long-distance services.

Today, more than 25 years after the start of HSR services, it is possible to analyse the territorial impact of this new infrastructure, more specifically on the economic development of cities and regions with this new transport service.

As De Rus [8] reminds us, infrastructure is a necessary condition for economic development, but it is not sufficient. Moreover, he states that productivity increases with public capital investment. However, the Law of Diminishing Returns is also applicable in this field. Therefore, the effect of the additional investment is lower when the network presents a more advanced state of expansion, as has been demonstrated in the Spanish case by Reig Martínez et al. [9].

It is now possible to contrast these approaches once again. In fact, the new HSR services produce a comparative economic advantage over cities or regions that do not have them. Consequently, those cities or regions with HSR services should show greater economic growth than those without such services. We can consider population growth to be an indicator of economic growth. Therefore, it is possible to make a comparative analysis of the population growth of cities/regions with/without HSR services and to test whether there is any relationship between them.

On the other hand, the population data series corresponds to the period 1991-2017. This period has seen three economic cycles: the crisis cycle from 1991-1996, the expansion cycle from 1997-2007 and the crisis cycle from 2008 to the present (today, it is difficult to establish an end date for this cycle). The situation is the same for the whole of Spain. Therefore, those cities or regions with HSR services, in general, should have taken advantage of their comparative benefit across all the economic cycles.

\section{OBJECTIVES}

The objective of this research is to test the relationship between the new HSR services and the economic development of urban areas with the new services, measured by the population growth indicators. A previous study focused on cities. Now, this study has focused on urban areas (UA) or metropolitan areas (MA). Please note that the core city or city centre, where the railway stations are usually located, can have lower growth than that of the urban area as a whole because, usually, the city centre or city core is absolutely built-up, so that significant urban development is not possible.

Specifically, the research aims to discover whether those urban areas where the new HSR services have been implemented have experienced greater economic growth, as measured by the growth of their population, than those where HSR services have not been implemented or if there have been changes in the trend of population growth before and after the start of services.

On the other hand, in Spain, economic activities are concentrated in the coastal zones and Madrid, but the HSR network connects cities with Madrid, not with the coastal cities between them. Consequently, in addition, it is interesting to analyse and compare the growth with that of coastal urban areas without HSR services.

\section{METHODOLOGY}

The analysis focuses on the growth that has occurred in urban areas with HSR services and compares it with those that do not have such services and, specifically, with coastal urban areas. 
The "Instituto Nacional de Estadística" (INE) (National Institute of Statistics, in English) has annual data on inhabitants for all the municipalities of Spain through the "Register of Inhabitants" from 1996. Before that, data on municipal inhabitants exists in each census, which does not take place annually but only in certain years. In particular, the last Census of Inhabitants and Houses occurred in 1991. The first HSR services started in 1992.

The methodologies for collecting inhabitants' data differ in the Census and the Register of Inhabitants, but our interest is focused on growth, not on the total number of inhabitants, in order to perform a comparative analysis. So, this difference is not relevant.

On the other hand, the Ministerio de Fomento of Spain publishes data about urban areas in Spain and the list of municipalities in each area, according to homogeneous criteria, for the whole of Spain [10]. It is possible to obtain the population for each urban area according to these data. This study has been carried out with the urban areas identified in 2016, with population data from 2015.

The work analyses three matters:

- The population growth of all urban areas with HSR services compared with the population growth of the rest of Spain without HSR services.

- The population growth of each urban area with HSR services compared with the population growth of the rest of Spain without HSR services.

- The population growth of urban areas with HSR services compared with the population growth of coastal urban areas without HSR services.

To perform the analysis, it is necessary to consider that urban areas with/without HSR services change when HSR services begin in new areas. The indicator selected to show the population growth is shown in eqn (1) below

$$
G I_{n+1}=\frac{P_{n+1}+P_{n}}{P_{n}} G I_{n},
$$

where $\mathrm{P}$ is the population in year $n+1$ or $n$ and GI is the Growth Index in year $n+1$ or $n$. The year 1991 has been established as a 100 base, that is, $\mathrm{GI}_{1991}=100$ for all variables. Besides, according to the "Register of Inhabitants", the population refers to the population on the first of January each year. So, the indicator GI calculated with this data shows the growth produced in the previous year. The last GI calculated is for growth in 2016.

When a year is one in which new cities have acquired HSR services, the whole populations of cities with/without HSR services are recalculated.

The geographical area of metropolitan areas changes over time, as commuting travel increases, and new areas or municipalities are integrated into them, as shown by Feria Toribio and Martínez Bernabea [11]. This work solves this problem by fixing the geographical urban area in 2015. In fact, before 2015, in general, the urban area could be minor but, in this case, cities outside urban areas usually have little growth and, in consequence, their influence on population urban growth is very small. Note that the analysis is based on population growth not on total population. In this way, although the total population of an urban area may be erroneous in years prior to 2015, the population growth rate will be correct.

\section{RESULTS AND DISCUSSION}

4.1 Population growth of all cities with HSR services versus all cities without HSR services

Fig. 3 shows the evolution of the Population Growth Index for all cities and metropolitan/urban areas with HSR services, for the whole of Spain, and for all cities 
(excluding cities in previous metropolitan/urban areas) without HSR services. The graph shows that those cities without HSR services have a Growth Index similar to that of Spain, with the exception of last year, while the cities with HSR services have had a greater GI since about 2000 .

In this graph, it is possible to find three situations in relation to periods of economic expansion and crisis. The first period, from 1991-1996, was a period of economic crisis. During this time, all cities, with or without HSR services, had a similar GI without distinction. In the second period, from 1997-2007, a period of economic expansion, cities without HSR services showed similar growth to that of the whole of Spain, while cities and MA/UA with HSR services showed a little bigger growth. Since 2008, during the second period of economic crisis, the behaviour of cities with/without HSR services has differed. The general behaviour shows that cities and MA/UA with HSR services have greater growth than cities without HSR services and, in addition, this difference in growth increases year by year. On the other hand, since 2015, the trend has changed: cities and MA/UA with HSR services have increasing populations, while cities and MA/UA without HSR services have decreasing populations. In recent years, the growth gap has grown noticeably. In this situation, the average growth of Spain is not representative. Probably, this different behaviour relates to the beginning of an economic reactivation process during the crisis period. That is, some metropolitan/urban areas have begun to reactivate economically, while others have not.

On the other hand, the situation is not homogeneous for all cities, metropolitan areas and urban areas. The following sections present the analysis, case by case, for the metropolitan and urban areas. In this study, areas with more than 600,000 inhabitants in 2015 are named metropolitan areas (or MA), while the others are named urban areas (or UA).

4.2 Population growth of each urban area with HSR services versus all cities and urban areas without HSR services

The first HSR services started in 1992 and connect the cities of Sevilla, Córdoba, Puertollano, Ciudad Real and Madrid. Fig. 4 shows the Growth Indexes of the MAs of Sevilla and Madrid, and the UAs of Ciudad Real and Córdoba.

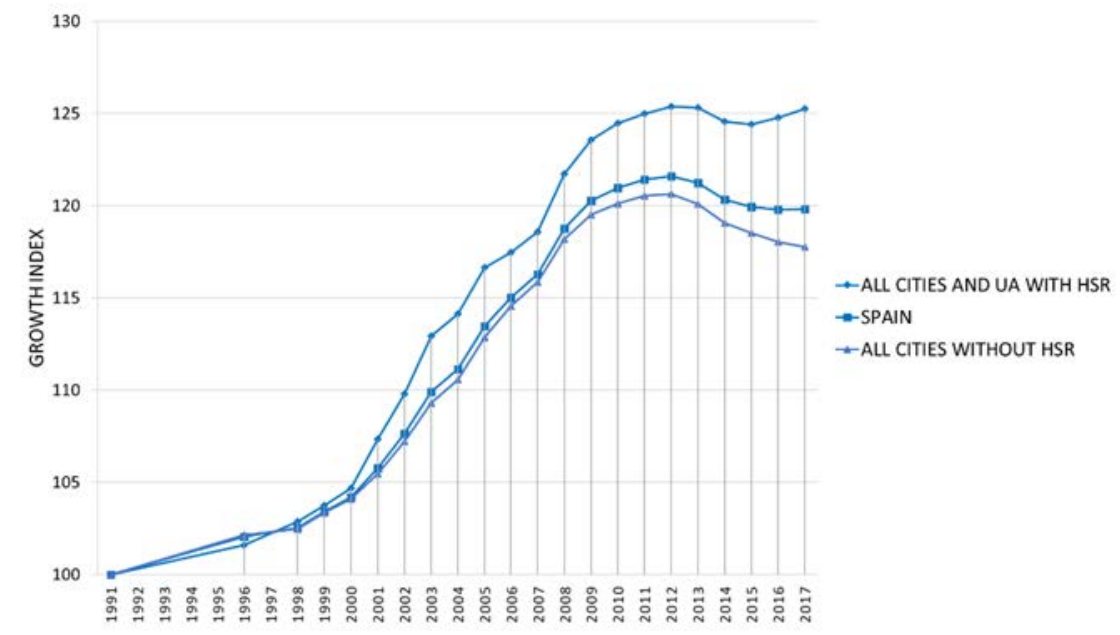

Figure 3: Population Growth Index evolution for cities and metropolitan/urban areas with/without HSR and for Spain as a whole. 


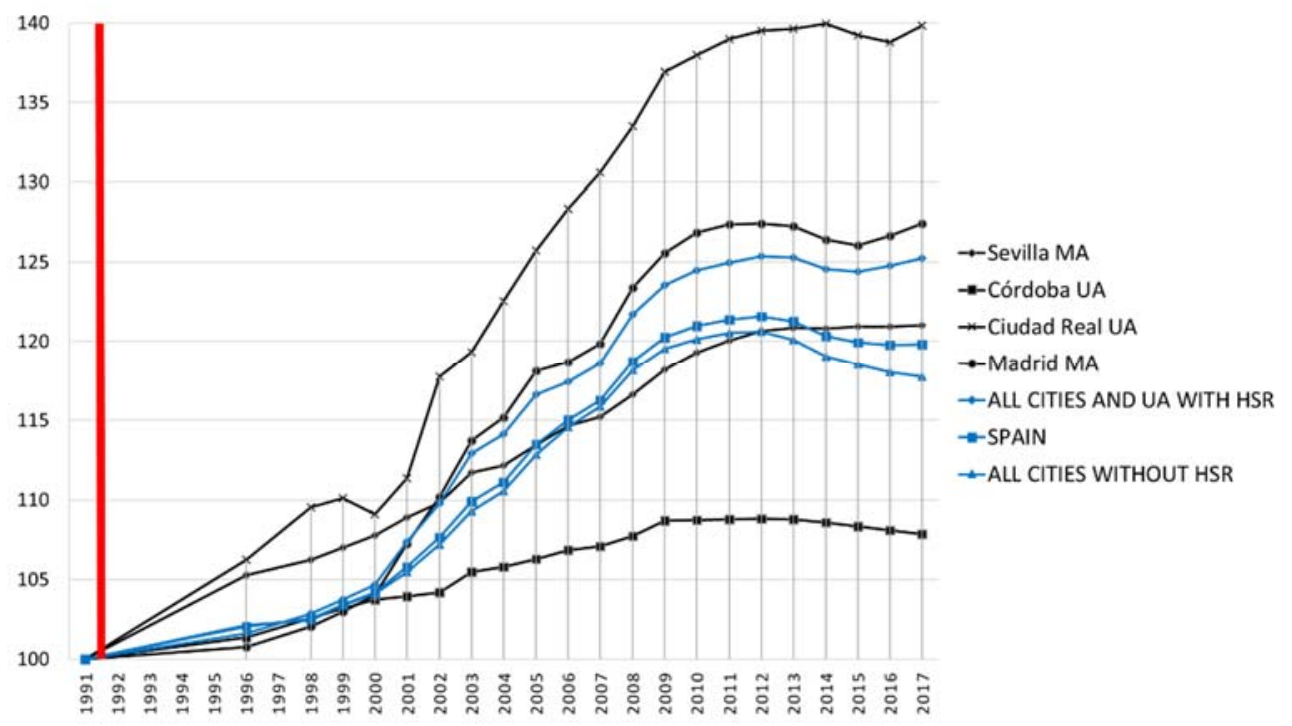

Figure 4: Population Growth Index for metropolitan/urban areas where HSR started services in 1992.

As you can see, Madrid MA and, especially, the UA of Ciudad Real demonstrate an evolution similar to or greater than that of MAs/UAs with HSR services. These services allow commuting between Ciudad Real and Madrid and, in consequence, the integration process of Ciudad Real UA into the metropolitan area of Madrid.

On the contrary, the UA of Córdoba presents a lower level of growth, and Seville MA displays a lower level of growth from when HSR services started in 1992 until 2009. After this year, it maintained greater growth than that of Spain as a whole and cities without HSR services. That means, in fact, that HSR services are not associated with the economic development of Seville. However, from 2012, Seville has not had an increase in growth index, which is similar to Madrid or Ciudad Real. In fact, this plateaued between 2012 and 2017. The case of Sevilla shows that new infrastructure is necessary but not sufficient to bring about economic development.

Fig. 5 shows the evolution of the GI of the MAs/UAs of Guadalajara, Zaragoza and Lleida, where HSR services began in 2004. It can be seen that the case of Guadalajara is similar to that of Ciudad Real. Curiously, this is a special case because Guadalajara's HSR station is very far from the city centre and commuting to Madrid is usually done by conventional train, not by HSR services. Again, the most probable cause of this growth is the integration of Guadalajara into the metropolitan area of Madrid.

In contrast, Zaragoza MA presents growth similar to that of cities without HSR services. After HSR services began, the evolution of growth was parallel to that of MAs/UAs with HSR services. Recent years also show an increase, which is similar to the general behaviour of MAs/UAs with HSR services.

Lleida UA displays particular behaviour. After HSR services started, from 2004-2014, it showed high growth, but, since 2015, the trend has changed, and growth has decreased, in contrast to the general trend of MAs/UAs with HSR services during this period. 


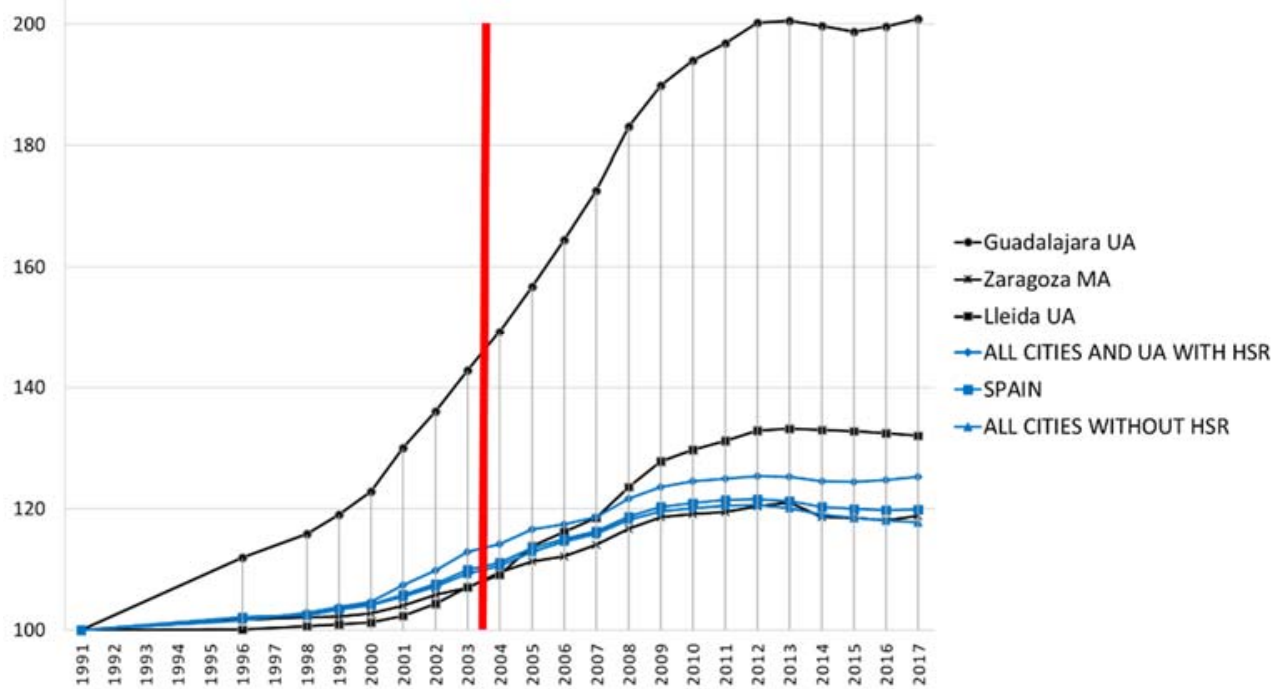

Figure 5: Population Growth Index for metropolitan/urban areas where HSR services started in 2004.

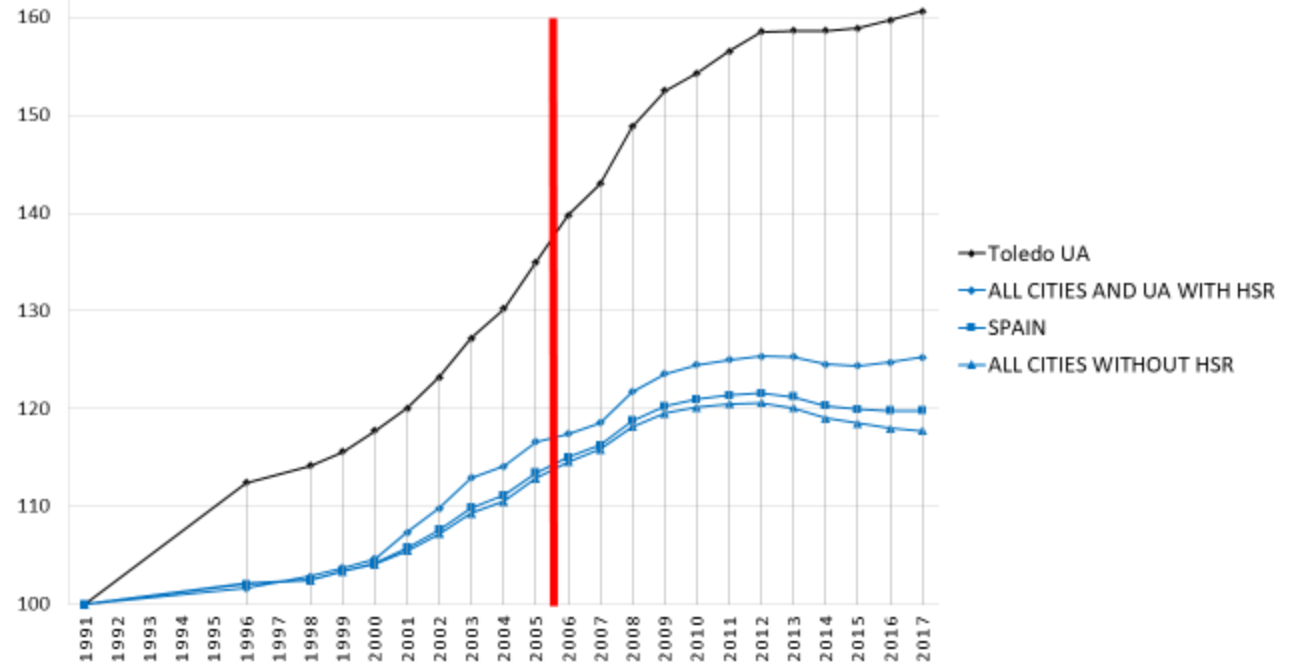

Figure 6: Population Growth Index for metropolitan/urban areas where HSR services started in in 2006. 
Fig. 6 shows the case of Toledo UA. This case is very similar to that of Ciudad Real and Guadalajara, in relation to Madrid.

The case of Tarragona UA, which is similar to Lleida, is shown in Fig. 7. However, Tarragona's HSR station is situated very far from the city centre, but Tarragona is closer to the metropolitan area of Barcelona.

Fig. 8 shows the growth behaviour of the MAs/UAs of Malaga, Segovia, Valladolid and Barcelona, where HSR services began operating in 2008.

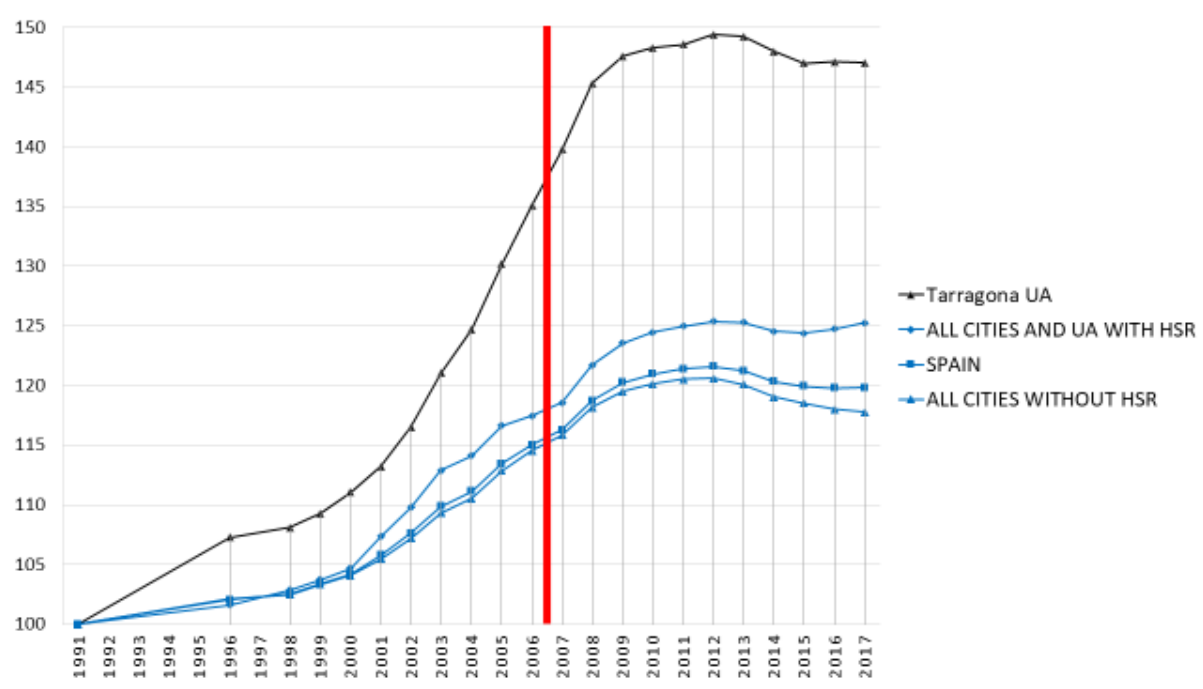

Figure 7: Population Growth Index for metropolitan/urban areas where HSR services started in 2007.

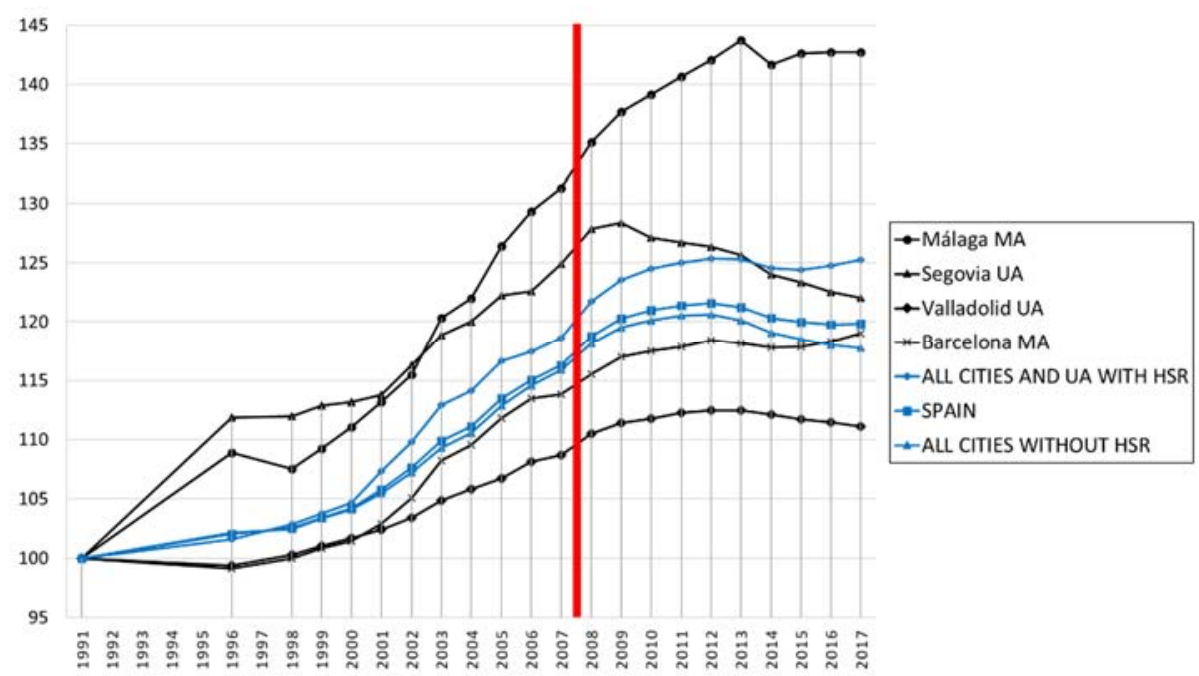

Figure 8: Population Growth Index for metropolitan/urban areas where HSR services started in 2008. 
As can be seen, Malaga MA shows that the trend is larger than Spain and MAs/UAs with HSR services before and after HSR services started in Malaga. Nevertheless, the behaviour change from 2013 shows that it has changed and is now a stable situation.

Barcelona MA presents a similar pattern to that of Zaragoza MA. It always shows a low level of growth, less than that of Spain. Since HSR services started, the Growth Index trend has been similar to that of MAs/UAs with HSR services, and since 2015, the change in trend shows a further increase.

Segovia and Valladolid present a decreasing growth trend, especially after the start of HSR services. These are difficult specific cases to understand. Segovia is close to Madrid, similar to Toledo or Guadalajara with an HSR station far from the city centre. However, growth changes and begins to decrease when HSR services start. The case of Valladolid UA is similar, but the change is not so intense.

Fig. 9 shows the case of Valencia MA. This case is similar to those of Barcelona and Zaragoza. Before HSR services started, the growth gap between Valencia and MAs/UAs with HSR services increased; after HSR services began, their growth trends were parallel.

Finally, Fig. 10 shows the cases of the MA of Alacant/Elx and the UAs of Girona and Albacete. The case of Girona UA is similar to those of Toledo, Ciudad Real and Guadalajara, but in relation to Barcelona. In fact, the HSR services facilitate commuting from Girona to Barcelona. Albacete UA and Alacant/Elx MA display large growth before HSR services started. However, after HSR services were instigated, the trend changes to be parallel to that of MAs/UAs with HSR services.

4.3 Population growth of urban areas with HSR services versus main coastal urban areas without HSR services

To complete the analysis, Fig. 11 shows the Growth Index of main coastal metropolitan areas without HSR services.

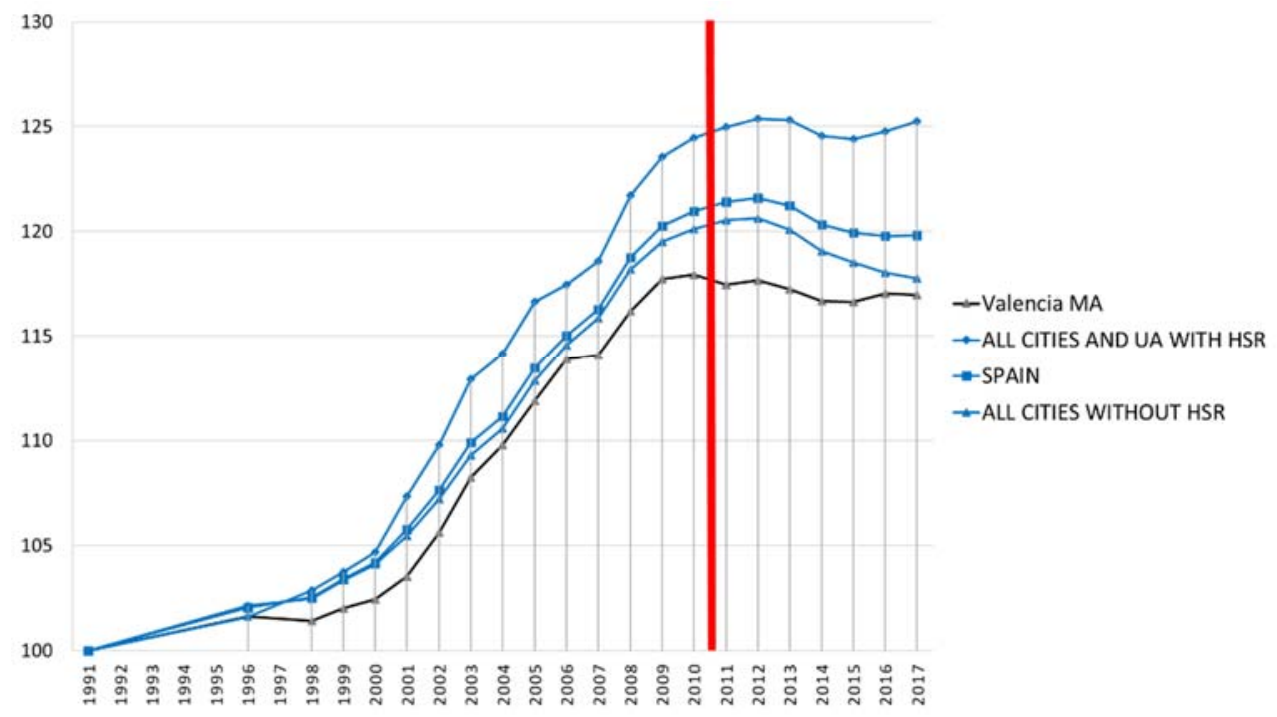

Figure 9: Population Growth Index for metropolitan/urban areas where HSR services started in 2011. 


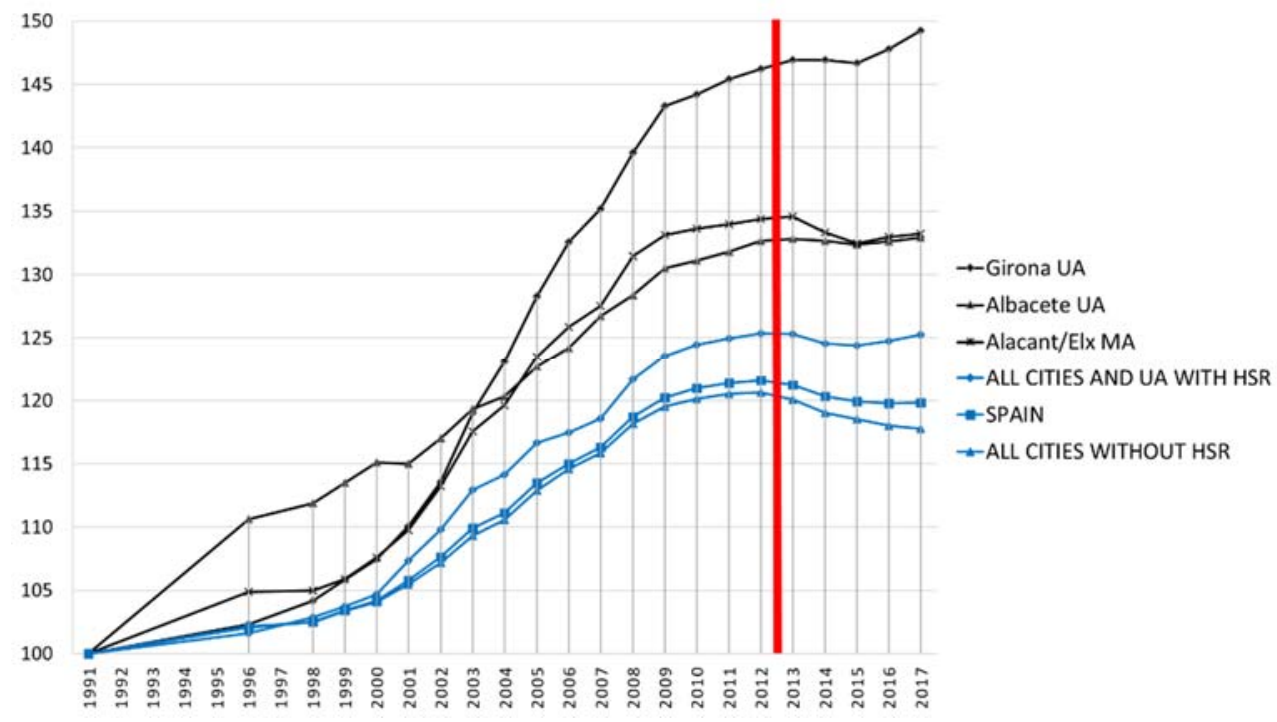

Figure 10: Population Growth Index for metropolitan/urban areas where HSR services started in 2013.

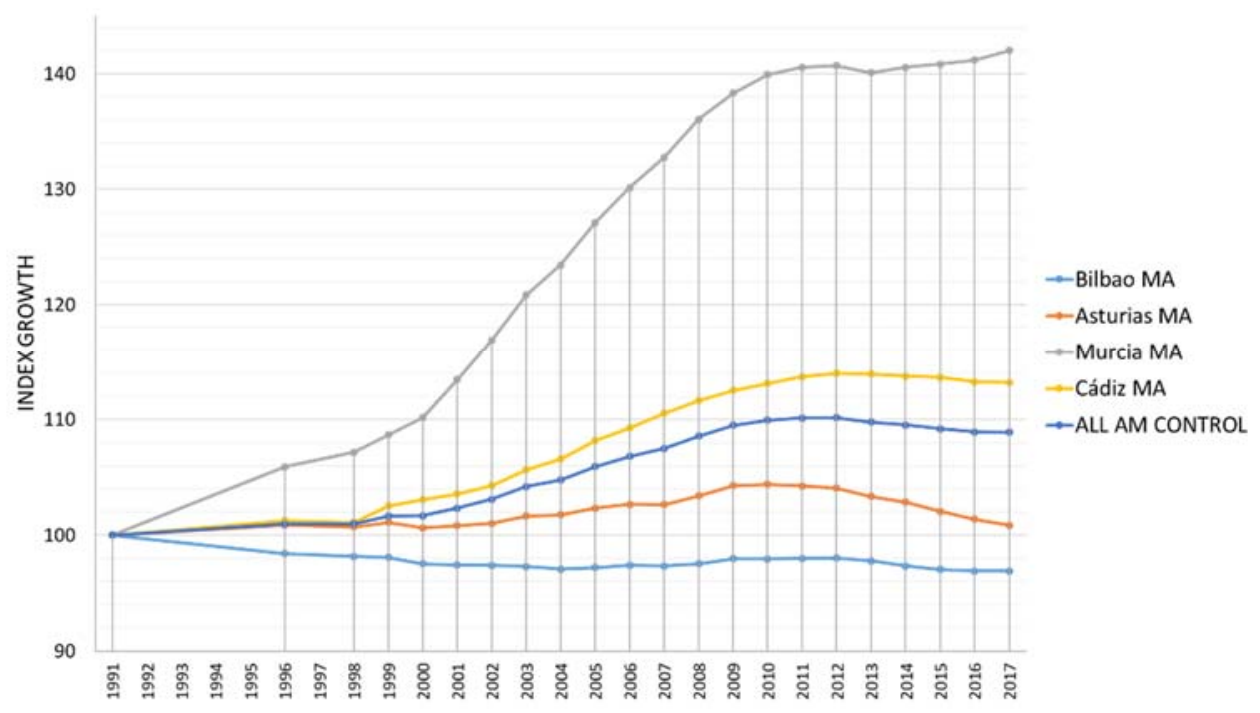

Figure 11: Population Growth Index for main coastal metropolitan areas of Spain without HSR services.

We can observe three cases. Murcia MA, which, although not exactly on the coast, is located very close to it, has evolved in a similar way to that of MAs/UAs with HSR services. Asturias and Cadis present a decreasing trend, especially in recent years. This fact indicates that they are not in the process of economic reactivation. Finally, Bilbao MA demonstrates 
stabilized evolution, especially in recent years. In general, but with some exceptions, growth is less than that of MAs/UAs with HSR services.

According to these data, the behaviour of metropolitan and urban areas without HSR services is not homogeneous. In fact, there are metropolitan areas, such as Murcia, with a very high Growth Index, despite not having HSR services, while the general trend of the whole of control group of coastal metropolitan areas without HSR services, shown on the graph as "ALL AM CONTROL", differs. These facts show that population evolution can be the result of different causes, and innovations in transport or new infrastructure are not synonymous with economic development.

\subsection{Synthesized map of HSR's territorial impacts by population index growth}

Fig. 12 shows a synthesis of the results of the analysis. Note that the analysis considers the Growth Index as an indicator of economic development. Spain has two big metropolitan areas, Madrid and Barcelona, and other lower metropolitan areas with more than 600,000 inhabitants. The MA of Madrid is the only big metropolitan area that presents a positive evolution of its Growth Index, greater than the general evolution. Malaga, a Mediterranean coastal MA, also displays this positive evolution.

The other cases showing positive evolution are those of UAs close to other big MAs, and they are probably an expression of integration into the MA through commuting journeys. These are the cases of Guadalajara, Toledo and Ciudad Real, in relation to Madrid, and of Girona in relation to Barcelona. Different authors, such as Wheeler [12], explain this as the general process of the expansion of metropolitan areas.

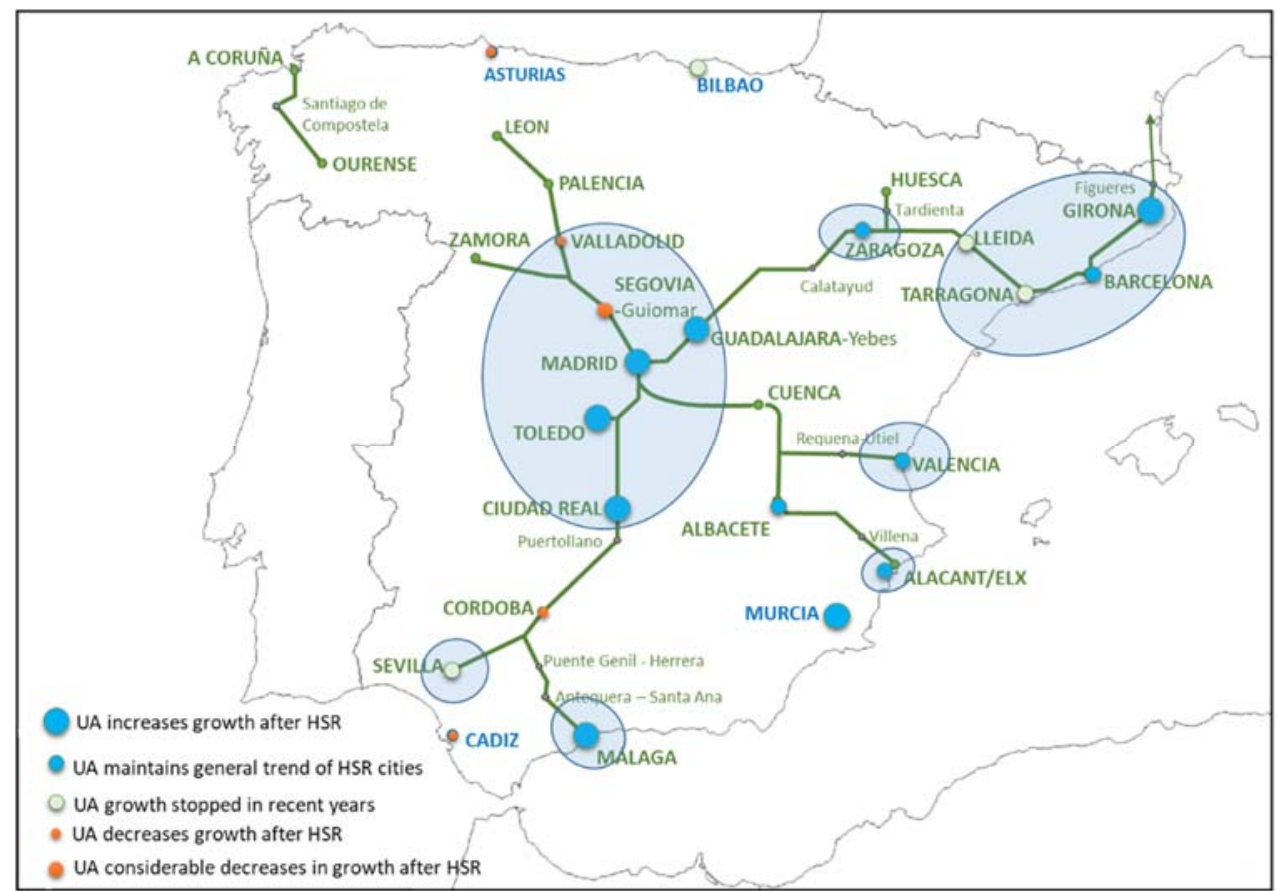

Figure 12: Map showing the main territorial impact of HSR services in Spain. 
Nevertheless, this phenomenon is not homogeneous, and there are exceptions. For example, Valladolid, and especially Segovia, close to Madrid, present negative evolution. The cases of Tarragona and Lleida, in relation to Barcelona, display stabilized evolution but not a process of integration into the MA. In these cases, additional analysis is necessary to understand what is happening. Maybe the location of the HSR station (very far from the city centre in the cases of Segovia and Tarragona), or the behaviour of stakeholders or the distance to the core city can explain the situation.

Other main metropolitan areas, such as Valencia, Zaragoza, Alacant/Elx and Albacete, show moderate positive evolution, especially from 2015 until today. Seville MA, the first main city to be connected with Madrid by HSR, displays general negative evolution, changing to stabilized growth in the most recent period.

The main coastal metropolitan areas without HSR services do not follow a homogeneous pattern. For example, Murcia's Growth Index is very positive, similar to or better than the evolution of MAs/UAs with HSR services. Bilbao presents a stabilized situation, and Asturias and Cadis display a decreasing trend.

In addition, we can consider that HSR services are adequate for distances of between approximately 300 and $500 \mathrm{~km}$. But, as can be seen on the map, the cities in the process of integrating into the MAs of Madrid and Barcelona, which display higher growth, have lesser distances to travel.

The cities located in the Mediterranean Corridor, despite currently, in general, showing positive evolution, are not connected with one another. The radial design of the network benefits Madrid.

\section{CONCLUSIONS}

From the analysis, the following main conclusions can be drawn. All cities and metropolitan areas have their own economic dynamics, usually independent of HSR services. HSR services can help these dynamics, but that is not necessarily the case. Therefore, HSR services are not synonymous with economic progress. Hence, the territorial impacts are not homogeneous, and it is possible to identify different patterns.

The main metropolitan areas with a positive GI trend are Madrid and Malaga. Madrid has probably benefited from the radial network, since all the connections pass through Madrid.

Some urban areas close to the big metropolitan areas also display high growth. That is shown in the cases of Guadalajara, Toledo, Ciudad Real, in relation to Madrid, and of Girona in relation to Barcelona. In contrast, this process has not been repeated in other urban areas with similar locations, such as Segovia and Valladolid, near to Madrid, and Tarragona and Lleida, near to Barcelona.

Other metropolitan areas present low growth from 2012 with a trend that changes since 2015, such as Barcelona, Valencia, Zaragoza, Alacant/Elx and Albacete. The trend in Seville since 2015 is stable.

The coastal metropolitan areas without HSR services also display different patterns: decreasing growth, stabilized situation or even similar growth to the maximum of urban areas with HSR services (the case of Murcia).

Finally, the map shows the absence of connections between the cities of the Mediterranean corridor, despite the fact that they show significant economic activity.

\section{REFERENCES}

[1] ADIF (Administrador de Infraestructuras Ferroviarias), Online. www.adif.es. Accessed on: 14 Jul. 2018. 
[2] VIA LIBRE Spanish Railway Journal, High speed atlas in Spain. Year XLVIII, April 2012. Online. www.vialibre.org. Accessed on: 14 Dec. 2017.

[3] Ministerio de Fomento (Spain), Statistical information. RENFE OPERADORA. Online. $w w w$. fomento.gob.es/BE/?nivel=2\&orden $=07000000$. Accessed on: 24 May 2018.

[4] Albalate, D. \& Bel, G., La experiencia internacional en alta velocidad ferroviaria, FEDEA: Mar. 2015. ISSN 1696-750. Online. www.fedea.es. Accessed on: 24 May 2018.

[5] Albalate, D. \& Bel, G., The Economics and Politics of High-Speed Rail. Lessons from Experiences Abroad, Lexington Books: Lanham, 2012.

[6] Miralles i Garcia, J.L., Integration of high-speed train stations in cities: the case of Spain and Valencia city. International Journal of Transport Development and Integration, 1(4), pp. 677-694, 2017. DOI: 10.2495/TDI-V1-N4-677-694.

[7] Bel, G., España, capital Paris, Ediciones Destino: Madrid, 2010. ISBN 9788423343140.

[8] De Rus, G., La política de infraestructuras en España Una reforma pendiente. FEDEA Documentos de Trabajo, 8, 2015. Online. www.fedea.es. Accessed on: 24 May 2018.

[9] Reig Martínez, E. et al., Competitividad, crecimiento y capitalización de las regiones españolas, Fundación BBVA-IVIE, 2007.

[10] Ministerio de Fomento (Spain), Atlas estadísticos de las áreas urbanas. Online. www.fomento.gob.es/MFOM/LANG_CASTELLANO/_ESPECIALES/

SIU/ATLAS/. Accessed on: 24 May 2018.

[11] Feria Toribio, J.M. \& Martínez Bernabeu, L., La definición y delimitación del sistema metropolitano español: permanencias y cambios entre 2001 y 2011. Revista Ciudad y Territorio. Estudios Territoriales, 187, Ministerio de Fomento: Madrid, pp. 9-24, 2016.

[12] Wheeler, S.M., The evolution of built landscapes in metropolitan regions. Journal of Planning Education and Research, 27(4), pp. 400-416, 2008. DOI: $10.1177 / 0739456 \times 08315889$. 